\title{
Investigating Infertility-Related Stress and Adoption in Iranian Infertile Females with Assisted Reproductive Technology Failure
}

\author{
Tayebe Hajiyan, ${ }^{1}$ Poorandokht Afshari, ${ }^{2,}{ }^{*}$ Mohammad Reza Abedi, ${ }^{3}$ and Esmaeil Hashemi ${ }^{4}$ \\ ${ }^{1}$ Department of Nursing and Midwifery, Ahvaz Jundishapour University of Medical Sciences, Ahvaz, IR Iran \\ ${ }^{2}$ Reproductive Health Promotion Research Center, Ahvaz Jundishapour University of Medical Sciences, Ahvaz, IR Iran \\ ${ }^{3}$ Counseling Department, Psychological and Education Science Faculty, University of Isfahan, Isfahan, IR Iran \\ ${ }^{4}$ Industrial and Organizational Department, Shahid Chamran University of Ahvaz, Ahvaz, IR Iran \\ "Corresponding author: Poorandokht Afshari, Reproductive Health Promotion Research Center, Ahvaz Jundishapour University of Medical Sciences, Ahvaz, IR Iran. Tel: \\ +98-921757323, E-mail: p_afshary@yahoo.com
}

Received 2016 June 10; Revised 2016 August 01; Accepted 2016 August 24.

\begin{abstract}
Background: Using Assisted Reproductive Technologies (ART) is a stressful experience marked by lengthy and invasive medical procedures, high financial cost and relatively low success rate. Adoption is considered as one of the infertility treatment methods that can have great impact on healing emotional problems of infertile couples and can improve their relationship.

Objectives: The current study aimed to investigate infertility-related stress and adoption in Iranian Infertile females with a history of ART failure, during year 2015.

Methods: This was a cross sectional study in which 30 Iranian infertile females, 30 to 45 years old, with primary infertility of five years or more, and history of ART failure, were investigated. Data collection instruments included the questionnaire of infertility and demographic factors, fertility problem inventory (FPI) and adoption questionnaire. The data were analyzed by SPSS V22, using descriptive statistics and Pearson test to assess possible correlations.

Results: The mean of the total score of infertility stress of the participants was $186.1 \pm 29.46$ (moderate to high). All participants showed some level of infertility stress. The mean score of adoption was $38.4 \pm 3.73$ (moderate acceptance), $53.33 \%$ of which showed moderate acceptance. There was no relationship between infertility stress and adoption (correlation $=-0.13, \mathrm{P}=0.48$ ).

Conclusions: Infertile females with a history of unsuccessful ART had a high level of infertility stress and moderate acceptance of adoption. We must pay more attention to psychological aspects of infertility and failure of treatment. There is an obvious need to increase society awareness about adoption and promote "adoption" as a sensible choice to form a family.
\end{abstract}

Keywords: Infertility, Infertility Treatment Failure, Psychological Stress, Adoption

\section{Background}

Fertility has always been one of the most important functions of a family (1). When a man and woman realize that they may never have a child, they face a crisis caused by infertility. This situation can negatively affect their entire life (2). There is infertility in 10 to $15 \%$ of couples (3). The total incidence of infertility in Iran has been reported as $13.2 \%$ (4).

Infertility is not only a medical problem but also a crisis of social life. It can influence interpersonal, marital and social relationships and cause significant emotional and psychological damage (5). It results in the occurrence of a wide range of emotional and physiological disorders, which may be destructive and have a damaging and lasting impact on their lives (6).

Infertility stress includes a series of symptoms, which are caused by infertility and are similar to many of the symptoms of post traumatic stress disorder (PTSD). This is specifically true regarding thoughts and emotions related to infertility, and attempts to become free of such thoughts and emotions (7).

Evidence is emerging on an association between stress of fertility treatment and patient dropout and pregnancy rates (8). According to the study by Boivin (2004), infertility stress affects the treatment results directly and indirectly (9) but further research is needed to understand the association between distress and fertility outcome, as well as effective psychosocial interventions (8).

Despite the recent success in infertility management, $2 \%-7 \%$ of couples will have no child at the end of their reproductive age (10) and only half of the infertile couples will have a live birth by infertility treatments (11). The success rate of ART treatments for infertile females of less than 35 years of age is $9 \%-20 \%$ for Intra Uterine Insemination (IUI) and 31\% - $46 \%$ for in vitro fertilization (IVF) $(12,13)$.

Leiblum et al. discovered that infertile females do not lose hope to have a biological child even after long periods since discontinuation of infertility treatments (14).

For many infertile couples, who are resistant to treat- 
ment, this situation is similar to losing or mourning for a family members' death (grief) and will result in severe depression (15).

Adoption is considered as one of the infertility treatment methods that can have great impact on healing the emotional problems of infertile couples (16) and can improve their relationship. Through adoption, the couples can experience the pleasure of being a mother or father and can overcome the psychological and emotional problems of the absence of a child in their life (17). The anxiety of couples together with the experience of being parents for the first time may bring them much tension and stress (18).

According to Thorn et al. (2010), adoption is often the last resort since the majority of infertile couples initiate medical treatment without considering alternatives, hoping that the treatment will be successful (19), and Physicians mostly discuss adoption with their patients after the failure of medical treatments (20).

A five-year follow-up of a cohort showed that $6 \%$ of couples had adopted one or more children. The same study showed that $74.7 \%$ of the women had a delivery within the five-year follow-up of the cohort (21). This likely explains some of the discrepancy between the proportion of participants, who had positive attitudes towards pursuing adoption and the proportion, who ended up seeking adoption (22). Additionally, to the best of our knowledge, there are very few studies reporting infertility-related stress and attitude towards adoption, and the relationship between these two important variables have not been considered.

\section{Objectives}

The current study aimed to investigate infertility stress and adoption in infertile females, who had a history of unsuccessful assisted reproductive technology (ART) treatments.

\section{Methods}

This was a cross sectional study, in which 30 infertile females, who had referred to "Isfahan fertility and infertility center" and "infertility clinic of Esfahan Shahid Beheshti hospital" and had the criteria of entering the study, were investigated between September and November, 2015.

The criteria included age of 30 to 45 years, primary infertility of five years or more, history of ART failure (history of three unsuccessful IUI or one IVF failure), no history of psychological disease, and tendency to participate in the study.
Data collection instruments included the questionnaire of infertility and demographic factors, fertility problem inventory (FPI) and adoption questionnaire.

The validity and reliability of Newton infertility stress questionnaire (FPI) in Iran was calculated by Alizade et al. (2005). To achieve the reliability in a sample of 30 infertile females, the Cronbach's alpha for stress in social, sexual and relational aspects, life without a child, need to be a parent and total stress was estimated as $0.78,0.77,0.78$, $0.75,0.84,0.91$, respectively (23). A score between 0 and 97 showed low infertility stress, 98 - 132 moderate, 133 - 167 moderate to high, 168 and more very high infertility stress.

In this study, "the questionnaire of attitude towards adoption" produced by Bagheri et al. (16) was used to investigate adoption tendency. This questionnaire includes four parts: adoption, the point of view of society about adoption, communication with the main parents and discovering the adopted child's identity. Each of these parts includes five statements. The validity of this method was determined through content validity using the viewpoints of 20 specialists and faculty members from Mashhad and Kashan Medical Universities. Its reliability was confirmed with Cronbach's alpha $\alpha$ of 0.83 . Scores between 30 and 37 showed low acceptance, 38-52 moderate, and 53 and more high level of attitude towards adoption.

Infertile females, who had the inclusion criteria and had referred to "Isfahan fertility and infertility center" and "infertility clinic of Isfahan Shahid Beheshti hospital", after an interview wtih the researcher retrieval of medical records, answered the FPI and adoption questionnaire by themself in a quiet place. The purpose of the study was explained to everybody and they were ensured about their privacy.

This study was approved by the ethical committee of Ahwaz Jundishapour University of Medical Sciences with the following code IR.AJUMS.REC1394.368 .

Data was analyzed by SPSS V22, using frequency tables and descriptive statistics and Pearson correlation, to assess the relationship between variables. P values of $<0.05$ were considered statistically significant.

\section{Results}

Mean and standard deviation of the demographic factors are recorded in Table 1.

Infertility information, history of ART failure and discontinuing the treatment was recorded in Table 2.

There were only seven people (23.33\%), who did not consider infertility as a defect; the others mentioned that infertility was a defect. 
Table 1. The Frequency of the Demographic Characteristics of the Participants

\begin{tabular}{|lc|}
\hline Variable & Values $^{\mathbf{a}}$ \\
\hline Wife's age & $34.5 \pm 4.32$ \\
\hline Husband's age & $39.93 \pm 6.07$ \\
\hline Wife's level of education & \\
\hline \multicolumn{1}{|l}{ Less than diploma } & $5(16.66)$ \\
\hline Diploma & $12(40)$ \\
\hline BA & $9(30)$ \\
\hline MA and higher than MA & $4(13.33)$ \\
\hline Husband's level of education & \\
\hline Less than diploma & $9(30)$ \\
\hline Diploma & $8(26.66)$ \\
\hline BA & $8(26.66)$ \\
\hline MA and higher than MA & $5(16.66)$ \\
\hline
\end{tabular}

${ }^{\mathrm{a}}$ Values are expressed as mean \pm SD or No. $\%$.

Table 2. Infertility Related Characteristics of the Participants

\begin{tabular}{|cc|}
\hline Variable & Values $^{\mathbf{a}}$ \\
\hline Marriage duration & $12.03 \pm 5.58$ \\
\hline Infertility duration & $10.96 \pm 5.63$ \\
\hline Cause of Infertility & \\
\hline Male factor & $10(33.33)$ \\
\hline Female factor & $5(16.66)$ \\
\hline Both & $7(23.33)$ \\
\hline Unknown (idiopathic) & $8(26.33)$ \\
\hline History of unsuccessful IUI & $24(80)$ \\
\hline History of unsuccessful IVF & $20(66.66)$ \\
\hline History of unsuccessful microinjection & $18(60)$ \\
\hline History of discontinuing the treatment & $28(93.33)$ \\
\hline Yes & $2(66.66)$ \\
\hline No
\end{tabular}

${ }^{\mathrm{a}}$ Values are expressed as mean $\pm \mathrm{SD}$ or No. (\%).

Overall, $76.66 \%$ of the participants showed a history of unsuccessful pharmaceutical treatments with a minimum of four months and maximum of 24 cases.

Twenty-four participants (80\%) mentioned history of IUI failure with a minimum of once and maximum of five times.

Twenty participants (66.66\%) mentioned history of unsuccessful IVF and 18 participants (60\%) mentioned history of unsuccessful microinjection. The maximum number of unsuccessful IVF and microinjection was seven and six, re- spectively.

Twenty-four participants (80\%) had a history of discontinuing the treatment for two to four years, this is while only two participants (6.66) never interrupted their treatment. Furthermore, 14 people (46.66\%) mentioned financial problems as the reason of discontinuing their treatment. Of these, five people (35.71) mentioned financial problems as the only reason and the others noted financial problems together with some other problems such as boredom, frustration and psychological pressure. Eighteen people (60\%) mentioned that they discontinued their treatment because of psychological problems. Seven of these people (38.88) cited psychological problems as the only reason and $61.11 \%$ mentioned that financial problems besides psychological problems were their reasons for discontinuing their treatment. The participants mentioned husband's opposition, marital problems, opposite opinions of the physicians and failure as the other reasons for discontinuing their treatment.

Mean and standard deviation of infertility stress and adoption acceptance are recorded in Table 3.

Table 3. The Frequency of Infertility Stress and Adoption Acceptance

\begin{tabular}{|lc}
\hline Variable & Values $^{\mathbf{a}}$ \\
\hline Infertility stress & \\
\hline Social concern & $36.5 \pm 10.80$ \\
\hline Sexual concern & $27.43 \pm 7.60$ \\
\hline Relational concern & $43.16 \pm 8.76$ \\
\hline Life style without children & $48.13 \pm 9.66$ \\
\hline The need to be parent & $30.86 \pm 8.84$ \\
\hline Total score of infertility stress & $186.1 \pm 29.46$ \\
\hline Adoption & $8.56 \pm 1.96$ \\
\hline Adoption & $9.1 \pm 1.92$ \\
\hline Communication with the main parents & $10.53 \pm 1.64$ \\
\hline Society attitude toward the adoption & $10.2 \pm 1.19$ \\
\hline Identity discovery of the adopted child & $38.4 \pm 3.73$ \\
\hline Total score of adoption acceptance & \\
\hline
\end{tabular}

${ }^{\mathrm{a}}$ Values are expressed as mean $\pm \mathrm{SD}$.

Mean of the total score of infertility stress of the participants was $186.1 \pm 29.46$ (moderate to high). All the participants showed some level of infertility stress (no one showed low stress, two people: moderate stress, five people: moderate to high stress, 23 people: very high stress)

The mean score of the adoption acceptance was $38.4 \pm$ 3.73 (moderate acceptance), 53.33\% of which showed moderate acceptance and $46.66 \%$ low acceptance.

Thirteen participants (43.33\%) had already decided to 
accept adoption. Among them, 53.84\% mentioned 'loneliness' as the reason

For this decision, other reasons were God reward, family and friends' insistence, the need to be a parent (each of them six people, $46.15 \%$ ) and the wish to have an inheritor (two people, 15.38\%).

Seventeen participants (56.66\%) had not yet decided to accept adoption; of these people, $94.11 \%$ mentioned their hope to be cured as their reason for this decision.

Twenty-five participants (83.33\%) had not yet adopted a child. Among these people, $84 \%$ mention their hope to be cured as the reason. Other reasons included financial problems, legal problems, fear that the child might not like them, lack of availability and the fear that they might not be supported by others.

Seventeen participants (56.66\%) did not have a family history of adoption and 11 participants (36.66\%) mentioned a family history of adoption.

Only five participants (16.66) had met a psychologist, psychiatrist or consultant.

Table 4 shows the correlation between infertilityrelated stress and adoption. There was a negative relationship between the two variables, which means that increasing infertility-related stress led to decreased adoption, but this correlation wasn't statistically significant (Correlation $=-0.13, \mathrm{P}=0.48$ ).

Table 4. Correlation Between Infertility-Related Stress and Adoption

\begin{tabular}{|lcc|}
\hline Infertility-Related Stress & \multicolumn{2}{c|}{ Total Score of Attitude Towards Adoption } \\
\cline { 2 - 3 } & P Value & Pearson Correlation \\
\hline Social concern & 0.61 & -0.96 \\
\hline Sexual concern & 0.32 & -0.18 \\
\hline Relational concern & 0.88 & -0.02 \\
\hline Life style without a child & 0.2 & -0.23 \\
\hline The need to be a parent & 0.51 & 0.12 \\
\hline Total score & 0.48 & -0.13 \\
\hline
\end{tabular}

\section{Discussion and Conclusion}

The findings of this research indicated that infertile females with a history of unsuccessful assisted reproductive technology (ART) treatments had a high level of infertility stress and moderate acceptance of adoption. There was a negative relationship between the two variables, which means that increasing infertility-related stress leads to adoption decrease, but this correlation wasn't statistically significant.
All the participants showed some level of infertility stress and most of them had moderate to high stress. This finding corresponds with the findings of Grill (1997) (24). Grill et al. believed that infertile couples mostly know infertility as the most stressful event in their life and describe the frequent and recurrent courses of treatment as frequent courses of crisis. The results of this research confirmed the findings of other researchers, who acknowledged infertility and the stages of its diagnosis and treatment as sources of stress and tension (25-27).

Beutel et al. (28), Thiering et al. (29) and Beaurepaire et al. (30) believed that the increase in the number of unsuccessful cycles will increase the women's tension. Jaaferpour et al. (31) believed that the difference between the treatment length mean and the period of patient's awareness of his/ her infertility and their divergent effect on the intensity of infertility stress indicated the severe impact of the diagnosis and treatment stages on the patient's psychological well-being. These researchers' findings are in the same line with our findings. In addition, all of our participants had a history of assisted reproductive technology treatments and mentioned at least one IVF failure or three unsuccessful IUI and they showed high level of infertility stress. These findings confirm Koropatrick et al. findings (32) and contradict Daniluk's study results, which indicated that the patients' stress will decrease after a period of time (33).

In this study, the participants received high scores in all aspects. This indicates the effect of infertility on all aspects of their life (social aspect, sexual aspect, relational aspect, life style with no child, the need to be parent).

Different researchers have different ideas about the effect of infertility on the couples' relationship. Many of them have reported a decrease of marital compatibility between the couples because of the infertility, while others believed that patience during the stages of infertility diagnosis and treatment will increase intimacy (27). Sandelowski et al. (34), by investigating 52 American couples, found that time is a very effective variable in marital compatibility of females. He believed that passing of time decreases marital compatibility of infertile females. Investigating the relationship between marital compatibility and infertility stress in Iran, Jaaferpour et al. (31) concluded that the more stress people experience due to infertility, the less marital compatibility they will have.

The results of this study showed that females with primary infertility of more than five years and history of ART failure, had a moderate attitude towards adoption; $46.6 \%$ had a weak attitude, and none of them had a high attitude. In the study of Bagheri et al. on a group without an adopted child, $10 \%$ of females and $18 \%$ of males had a weak attitude towards adoption and only $8 \%$ of females and $16 \%$ of males 
had a high attitude. In this study, none of the participants with an adopted child had a weak attitude towards adoption and there was a statistical difference between the two groups of participants with or without an adopted child ( $P$ $=0.00)(16)$.

Mohanty (2014), after interviewing1200 Singaporeans, concluded that most of the interviewees agreed with adoption as a form of family. Those, who cared about a biological relationship and were worried about the consequences of accepting adoption (compatibility, medical and behavioral problems, etc.), had a lower tendency towards adoption (35). Since in this study the interviewees did not have an infertility problem and their ideas were investigated generally, it cannot be concluded that there exists a high attitude toward adoption. Based on Mohanty's conclusion and the current research findings, there is an obvious need to increase society's awareness about adoption and promote "adoption" as a sensible choice to form a family.

As our findings indicate there was a negative relationship between the two investigated variables, which means that increasing infertility-related stress leads to a decrease in adoption. For many infertile couples, the time between diagnosis, treatment and outcome can be extensive and, if medical treatments are unsuccessful, couples are left to decide if they want to continue treatments, stop treatment, pursue adoption or stay childfree (36-38). In the study by Sundby et al. (39), 56\% of the women, who had started fertility treatment 10 years before, had considered divorce, and $17 \%$ actually ended the relationship. Furthermore, in some cultures, the concept of voluntary childlessness may not even exist (40). Infertility, childlessness and adoption have the potential to severely impact an individual's life (22), and since to our knowledge there are no studies focusing on the relationship between adoption and stress, specially infertility-related stress, thus more studies are required.

When examining couple's attitudes towards adoption, approximately one-fifth wanted to pursue adoption in the future, while more than a half were undecided regarding pursuing adoption at one-year follow-up. According to Letherby et al. (2010), adoption can be a challenge to one's self-identity, and thus expectations about one's relationship and future likely play a key role in decision-making (41). According to Thorn et al. (2010), adoption is often the last resort since the majority of infertile couples initiate medical treatment without considering alternatives, hoping that the treatment will be successful (19). The study by Peterson et al. (2015) showed that a small percentage of participants confirmed that they wished to pursue adoption after one year of medical fertility treatment, which may reflect that the majority of the participants still had the possibility of future ART cycles. The number of par- ticipants, who had a positive attitude towards pursuing adoption, was higher than the number of participants who ended up seeking adoption (22), As our findings suggest, the hope to be cured was the most important reason that prevented people from adopting. Leiblum et al. (14), in their investigations, recognized that infertile females did not lose hope to have a biological child even after long periods since discontinuing infertility treatment. This may complicate the 'process of liking; for the families, who adopt a child.

This study was limited by the use of a quantitative method, which revealed factors of importance regarding infertility patients' decision-making, but did not allow for further details, which could possibly explain the identified associations. Moreover, the sample size was relatively small. Future quantitative studies would benefit from including a larger number of participants, and enabling multivariate analyses, which could take potential confounders into account.

\section{Acknowledgments}

This study was part of an MSc thesis by Tayebe Hajiyan, which was supported by Ahvaz Jundishapur University of Medical Sciences. We appreciate the study participants, the research deputy vice-chancellor for research affairs at Ahvaz Jundishapur University of Medical Sciences, and the staff of "Isfahan fertility and infertility center" and "infertility clinic of Esfahan Shahid Beheshti hospital”.

\section{References}

1. Mahlstedt PP. The psychological component of infertility. Fertil Steril. 1985;43(3):335-46. [PubMed: 3979571].

2. Backshayash ARS. Women Infertility\& Dysfunction Disorder Sexual. 4th congress of sexual health. Tehran shahed university; .

3. Schmidt L. Infertile couples' assessment of infertility treatment. Acta Obstet Gynecol Scand. 1998;77(6):649-53. [PubMed: 9688243].

4. Direkvand Moghadam A, Delpisheh A, Sayehmiri K. The prevalence of infertility in Iran, a systematic review. Iranina J Obstet Gynecol Infertil. 2014;16:1-21.

5. Faramarzi M, Pasha H, Esmaelzadeh S, Jorsarai G, Mir Aghajani MR, Abedi S. Is coping strategies predictor of anxiety and depression in couple infertile?. Health. 2013;5(3).

6. McCarthy MP.Women's lived experience of infertility after unsuccessful medical intervention. J Midwifery Womens Health. 2008;53(4):31924. doi: 10.1016/j.jmwh.2007.11.004. [PubMed: 18586184].

7. Lin YN. Counselling a Taiwanese woman with infertility problems. Counsel Psychol Q. 2010;15(2):209-15. doi: 10.1080/09515070110104024.

8. Cousineau TM, Domar AD. Psychological impact of infertility. Best Pract Res Clin Obstet Gynaecol. 2007;21(2):293-308. doi: 10.1016/j.bpobgyn.2006.12.003. [PubMed: 17241818].

9. Boivin J. A review of psychosocial interventions in infertility. Soc Sci Med. 2003;57(12):2325-41. [PubMed: 14572840].

10. Kalantar SM, Kazemi MJ, Sheikhha MH, Aflatoonian A, Kafilzadeh F. Detection of Chlamydia trachomatis infection in female partners of infertile couples. Cell J. 2007;1(2). 
11. Leridon H. Can assisted reproduction technology compensate for the natural decline in fertility with age? A model assessment. Hum Reprod. 2004;19(7):1548-53. doi: 10.1093/humrep/deh304. [PubMed: 15205397].

12. Novak E. Berekand Novak Gynocology. Tehran: Golban; 2012.

13. Duran HE, Morshedi M, Kruger T, Oehninger S. Intrauterine insemination: a systematic review on determinants of success. Hum Reprod Update. 2002;8(4):373-84. [PubMed: 12206471].

14. Leiblum SR, Aviv A, Hamer R. Life after infertility treatment: a longterm investigation of marital and sexual function. Hum Reprod. 1998;13(12):3569-74. [PubMed: 9886552].

15. van den Akker OB. Coping, quality of life and psychological symptoms in three groups of sub-fertile women. Patient Educ Couns. 2005;57(2):183-9. doi: 10.1016/j.pec.2004.05.012. [PubMed:15911191].

16. Bagheri ALR, Omidi A, Esmaeili H. A Comparative Study of Psychosocial Factors Affecting Acknowledgment of Adoption In Couples With And Without Adopted Child. J Mashhad School Nurs Midwifery. 2009;9(1):51-8.

17. Sadock BJ, Sadock VA. Kaplan and Sadock's synopsis of psychiatry: Behavioral sciences/clinical psychiatry. Lippincott Williams \& Wilkins; 2011.

18. Farzadfard Z, Hooman HA. The role of parenting skills training on reduction stress of mothers and children's behavioral problems.J Iran Psychol. 2009;4(3):278-80.

19. Thorn P, Crawshaw M, Balen R. The shift from medical treatment to adoption: Exploring family building options. Adopt Infertil Messages Pract Res Person Exp. 2010:43.

20. Karami-Nouri RAM, Ardakani Z. Assessing of psychosocial aspects of infertility in Iranian doctors perspective. J Reprod Infertil. 2011:14-26.

21. Pinborg A, Hougaard CO, Nyboe Andersen A, Molbo D, Schmidt L. Prospective longitudinal cohort study on cumulative 5-year delivery and adoption rates among 1338 couples initiating infertility treatment. Hum Reprod. 2009;24(4):991-9. doi: 10.1093/humrep/den463. [PubMed: 19136480].

22. Petersen GL, Blenstrup LT, Peterson BD, Knudsen LB, Schmidt L. Impact of childlessness on life and attitudes towards continuation of medically assisted reproduction and/or adoption. Hum Fertil (Camb). 2015;18(2):121-7. doi: 10.3109/14647273.2015.1006691. [PubMed: 25687407].

23. Alizade TFM, Shahraray M, Alizadegan S. The correlation between self esteem and source of infertility stress in infertile men and women. $J$ Reprod Infertil. 2005;1:194-24.

24. Greil AL. Infertility and psychological distress: a critical review of the literature. Soc Sci Med. 1997;45(11):1679-704. [PubMed: 9428088].

25. Benazon N, Wright J, Sabourin S. Stress, sexual satisfaction, and marital adjustment in infertile couples. J Sex Marital Ther. 1992;18(4):27384. doi: 10.1080/00926239208412852. [PubMed: 1291698].

26. Collins A, Freeman EW, Boxer AS, Tureck R. Perceptions of infertility and treatment stress in females as compared with males entering in vitro fertilization treatment. Fertil Steril. 1992;57(2):350-6. [PubMed: 1735487].

27. Edelmann RJ, Humphrey M, Owens DJ. The meaning of parenthood and couples' reactions to male infertility. BrJ Med Psychol. 1994;67 ( Pt 3):291-9. [PubMed: 7803320].

28. Beutel M, Kupfer J, Kirchmeyer P, Kehde S, Kohn FM, SchroederPrintzen I, et al. Treatment-related stresses and depression in couples undergoing assisted reproductive treatment by IVF or ICSI. Andrologia. 1999;31(1):27-35. [PubMed: 9949886].

29. Thiering P, Beaurepaire J, Jones M, Saunders D, Tennant C. Mood state as a predictor of treatment outcome after in vitro fertilization/embryo transfer technology (IVF/ET). J Psychosom Res. 1993;37(5):481-91. [PubMed: 8350290].

30. Beaurepaire J, Jones M, Thiering P, Saunders D, Tennant C. Psychosocial adjustment to infertility and its treatment: male and female responses at different stages of IVF/ET treatment. J Psychosom Res. 1994;38(3):229-40. [PubMed: 8027962].

31. Jaaferpour M, Jahanfar S, Jamshidi R. Infertility related stress and marital life in Iranian infertile women who referred to Isfahan infertility treatment clinic. J Reprod Infertil. 2001;2(1):26-39.

32. Koropatnick S, Daniluk J, Pattinson HA. Infertility: a non-event transition. Fertil Steril. 1993;59(1):163-71. doi:10.1016/s0015-0282(16)55633-7.

33. Daniluk JC. Infertility: intrapersonal and interpersonal impact. Fertil Steril. 1988;49(6):982-90. [PubMed: 3371493].

34. Sandelowski M, Holditch-Davis D, Harris BG. Living the life: Explanations of infertility. Sociol Health Illness. 1990;12(2):195-215.

35. Mohanty J. Attitudes toward adoption in Singapore. J Fam Issues 2013;2:0192513X13500962.

36. Greil AL. Not yet pregnant: Infertile couples in contemporary America. Rutgers University Press; 1991.

37. Daniluk JC. Reconstructing their lives: a longitudinal, qualitative analysis of the transition to biological childlessness for infertile couples.J Counsel Dev. 2001;79(4):439.

38. Verhaak CM, Smeenk JM, Nahuis MJ, Kremer JA, Braat DD. Long term psychological adjustment to IVF/ICSI treatment in women. Hum Reprod. 2007;22(1):305-8. doi:10.1093/humrep/del355. [PubMed: 16973721].

39. Sundby J, Schmidt L, Heldaas K, Bugge S, Tanbo T. Consequences of IVF among women: 10 years post-treatment. J Psychosom Obstet Gynaecol. 2007;28(2):115-20. doi: 10.1080/01674820701447447. [PubMed: 17538819].

40. Remennick L. Childless in the land of imperative motherhood: Stigma and coping among infertile Israeli women. Sex Roles. 2000;43(11/12):821-41. doi: 10.1023/a:1011084821700.

41. Letherby G, Crawshaw M, Balen M. In: Adopting after Infertility: Messages from practice, research and personal experience. Crawshaw $\mathrm{M}$ Balen R, editors. London: Jessica Kingsley; 2010. pp. 29-42.When treatment ends: The experience of women and couples. 